\title{
Research
}

\section{Time to Talk? How the Structure of Dialog Processes Shapes Stakeholder Learning in Participatory Water Resources Management}

\author{
$\underline{\text { Melanie Muro }}^{1}$ and Paul Jeffrey ${ }^{1}$
}

\begin{abstract}
Public participation is increasingly viewed as a means to initiate social learning among stakeholders, resource managers, and policy makers rather than to ensure democratic representation. This growing understanding of participatory activities as learning platforms can be seen as a direct response to shifts in how natural resources management is framed, namely as uncertain, non-linear, and interlinked with the human dimensions. Social learning as it is discussed within the natural resources management (NRM) context features a process of collective and communicative learning that is thought to enable stakeholders to arrive at a shared understanding of a specific environmental situation and to develop new solutions as well as ways of acting together in pursuit of a shared ambition. Yet, although case-study research on social-learning processes provides multiple accounts of positive experiences, there are also reports of mistaken learning, the intensification of tensions or conflict, and failure to reach agreement or verifiable consensus. Based on results of a postal survey of stakeholder experiences in two involvement initiatives, we can draw two main conclusions: First, social learning is a multidimensional and dynamic process and, as such, evolves in stages and to various degrees. Second, stakeholder processes are shaped and affected by a multitude of factors that constrain the occurrence of learning processes and eventually limit the extent to which these can contribute to sustainable NRM. Foremost, the fact that the intensity of stakeholder learning differed in the two investigated initiatives reinforces the role organizational arrangements play in encouraging the type of communicative process necessary for stakeholder learning.
\end{abstract}

Key Words: participation; social learning; water framework directive

\section{INTRODUCTION}

Many voices are claiming that the development, management, and use of the world's water resources are undergoing major changes, a transition that is widely seen as overdue (Gleick 2003). There is a growing consensus that traditional technical and regulatory management approaches can only insufficiently address the complexity, uncertainty, and controversy that characterize contemporary water resources challenges. Against this background, new integrated and collaborative approaches are encouraged that emphasize social learning among stakeholders (Pahl-Wostl 2006). This trend is best illustrated by the European Water Framework Directive (WFD, Directive 2000/60/EC), today the single most important piece of water legislation in Europe. The WFD outlines an integrated and participatory River Basin Management (RBM) planning process, which specifically demands the active involvement of stakeholders in all design and implementation phases. The related guidance document on public participation, although recognizing the multiple benefits of stakeholder engagement — such as fostering trust in public institutions or improving the quality of decisionsspecifically encourages authorities responsible for drafting and implementing the RBM plans ("competent authorities") to ensure "that public participation becomes a way of learning about each others [sic] perspectives, views and knowledge, thereby providing the basis for negotiation between stakeholders about how to best implement the directive" (Working Group 2.9-Public Participation 2002:50 f.).
In essence, social learning describes a process of communicative action where multiple actors collectively learn about and develop an understanding of each others' interests, concerns, and preferences through dialog and deliberation, thereby opening up new opportunities to arrive at a shared diagnosis of a specific environmental situation as a precursor to agreeing upon interventions and solutions (Webler et al. 1995; Pahl-Wostl 2002; Röling 2002). Social learning is thought to be a naturally occurring social process that is intensified when stakeholders with different perceptions come together and engage with each other (Mostert et al. 2007). However, previous experiences show that the benefits associated with social learning are not always realized. For instance, Beierle and Konisksy's (1999) meta-analysis of 30 individual participation cases clearly shows that, although some initiatives successfully reduce conflict and increase trust among the involved parties, others had the opposite effect, sometimes even deteriorating relationships and increasing the potential for future conflict. Thus, rather than assuming that social learning is always warranted when stakeholders engage, we need to acknowledge that, although "social learning cannot be forced upon actors. [...] actors can be positively influenced by the creation of learning situations" (Rist et al. 2006:223). Yet, although research into factors that hinder or encourage social learning is growing, there is still a distinct need to specify participation conditions that create opportunities for learning. 
Against this background, the timing is ripe to systematically assess social learning in participatory water resources management (WRM) and thereby support responsible authorities in the design and management of effective learning-oriented engagement processes. In this paper, we report the results of a postal survey of stakeholder experiences in two involvement initiatives, one in Germany and one in Ireland. Our contribution is framed by two research questions: (1) To what extent are participatory processes characterized by social learning? (2) Which process characteristics encourage or hinder social learning? This paper is organized in five sections. First, extant literature about social learning in natural resources management (NRM) - and WRM in particular-is presented, with an emphasis on defining social learning and reviewing existing empirical evidence for its incidence and influence. We then proceed with a description of the study design and the investigated stakeholder initiatives, followed by a presentation of the survey data. Results are discussed in the context of extant knowledge, before concluding with a description of the insights gained from this inquiry and their implications for research and practice.

\section{SOCIAL LEARNING IN PARTICIPATORY WATER RESOURCES MANAGEMENT}

Learning is, regardless of the underlying theories and assumptions, essentially about change, more specifically the "act or process by which knowledge, skills, and attitudes are acquired" (Knowles et al. 2005). Views on how we learn and why and how change manifests itself vary considerably. Theories of social learning were first developed in the realm of social psychology and most prominently by the eminent psychologist Albert Bandura. His theory of social learning highlights the importance of observing and modeling the behaviors, attitudes, and emotional reactions of others. Human behavior is explained in terms of continuous reciprocal interaction between cognitive, behavioral, and environmental influences (Bandura 1977, 1986). In the field of NRM, Bandura's theory of social learning has been questioned as too narrow to embrace all the learning processes that are relevant to participatory water management (Pahl-Wostl 2002). As a consequence, the debate within the context of NRM draws from a wide variety of models and concepts in describing social learning within a participatory planning context, such as double- and triple-loop learning (Argyris and Schön 1978), experiential learning (Kolb 1984), and situated learning theories (Lave and Wenger 1991) but also fails to either deliver or consolidate an agreed-upon definition (Muro and Jeffrey 2008, Reed et al. 2010).

Despite the lack of a coherent theoretical foundation and a clear definition, a common understanding of what the process of social learning entails and of its outcomes and contributions to NRM does emerge from the literature. At the core of these models is a process of collective and communicative learning that may lead to changes in interrelated dimensions, including one or more of the following learning outcomes: relational changes (e.g., trust and relationships), cognitive changes (for example, generation of new knowledge and the transformation of views), and changes in the skills and technical competencies of the involved actors (e.g., conflict behavior). This study focuses relational and cognitive change at the individual level. Relational changes are associated with the development of new relationships and a strengthening of existing relationships, i.e., the way we feel and behave toward each other. These shifts involve a transformation in the way individuals perceive others, but also how they place themselves within the group. In other words, social learning is thought to not only affect an individual's attitude toward others but also their own motivations and orientations. Webler et al. (1995) speak of moral development, which results in a sense of self-respect and responsibility to oneself and others, a sense of solidarity, commitment to the common cause, and the adoption of collective interests as one's own (see also Frame et al. 2004, Rist et al. 2006). Further to transforming how individuals relate to other group members, social learning is thought to involve cognitive change, including both by the acquisition of knowledge as well as the transformation of views.

The described cognitive changes ideally initiate a shift from multiple to collective cognitions, a process often ascribed to social learning (Röling 2002). In the context of participatory resource management, multiple cognitions describes a situation that is commonly found at the start of a collaborative effort, where stakeholders holding different views based on their beliefs, experiences, and interests enter the process. By going through different stages of deliberation, reflection, and learning, stakeholders may accommodate and transform their views, eventually merging them into collectively held views and shared understandings of the system or problem at hand, agreement, and collective action (Röling 2002, Schusler et al. 2003, Pahl-Wostl 2006, Mostert et al. 2007). Special reference is often made to Habermas's theory on communicative rationality, which states that participants in interaction " $[\ldots]$ coordinate their plans for action by coming to an understanding about something in the world" (Habermas 1987:298). We would like to emphasize that, although scholars (e.g., PahlWostl 2006) have posited their assumption that social learning not only remains in the cognitive realm but that it may lead to joint practices and collective action, learning should not necessarily be understood as a precursor to behavioral change. Yet, realizing the cumulative benefits of social learning may help create more favorable conditions for cooperation and collective action. Reed et al. (2010:5) even go so far as to state "that if learning is to be considered "social learning," then it must: 1. Demonstrate that a change in understanding has taken place in the individuals involved. [...]. 2. Go beyond the individual to become situated within wider social units or communities of practice within society; [...]" As noted earlier, 
the study presented in this paper focuses on changes taking place at the individual level.

Figure 1 presents a compound model of social learning that captures the major claims made for the model in the literature and illustrates the links between the individual components of the model. It should be noted, however, that this understanding of social-learning processes is specific to NRM and not necessarily pertinent or useful to other contexts or problem domains. Despite a widening call for the adoption of a sociallearning approach to NRM, evidence substantiating the main claims put forward in the literature remains limited (Muro and Jeffrey 2008, Reed et al. 2010). Moreover, the literature also provides evidence less supportive of the social-learning model. There are reports of reinforced negative stakeholder perceptions (Schusler et al. 2003) or the intensification of conflict (Steyaert and Jiggins 2007). Research demonstrates that a multitude of factors may foster as well as hinder stakeholder learning (Webler et al. 1995, Schusler et al. 2003, Mostert et al. 2007), suggesting that some organizational arrangements may be more appropriate in fostering stakeholder learning than others. So far, however, there is little empirical evidence that could guide the practitioner to specific participation models or techniques that would help the design of learning-oriented engagement. Armitage et al. (2008:6) confirm that "the diversity of learning approaches or mechanisms suitable for complex NRM situations is a [further] source of uncertainty."

Fig. 1. A compound model of social learning drawn from literature

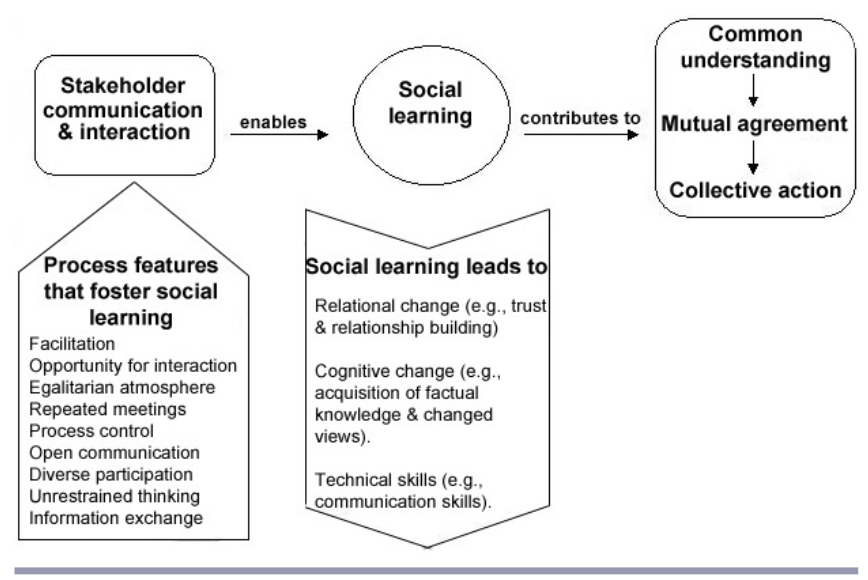

Although we acknowledge the wealth of studies exploring the relationship between stakeholder process and outcomes, previous research mainly focuses on defining factors for successful participation (e.g., Buchy and Hoverman 2000, Rowe and Frewer 2000, Webler et al. 2001, Abelson et al. 2003). A considerably smaller number of authors actually investigate the relationship between participatory process and outcome (e.g., Williams and Ellefson 1996, Beierle and Konisky 1999, Carr and Halvorsen 2001, Schuett et al. 2001, Beierle and Cayford 2002, Kessler 2004, Frame et al. 2004, Leach et al. 2002) and only a limited set of studies explore and demonstrate empirically how context, methods, or process design stimulate or hinder social-learning processes (e.g., Webler et al. 1995, Loeber 2003, Schusler et al. 2003, Rist et al. 2006, 2007 Ison et al. 2007, Mostert et al. 2007, Cundill 2010). Moreover, much of the presented evidence is anecdotal. Missing from the debate so far is a systematic investigation of social learning in different types of participatory processes (cf. Garmendia and Stagl 2010). If systematic differences exist in the extent to which different types of stakeholder platforms facilitate social learning, it should be possible to detect such differences through empirical analysis. By analyzing social learning in two participatory RBM initiatives, this study not only expands the still-limited empirical knowledge base on social leaning in stakeholder interaction, but also contributes to a better understanding of those process characteristics that promote social learning.

\section{METHODS}

We draw on data from a postal survey of two participatory RBM initiatives to explore these questions. A purposive rather than a random sampling strategy was adopted to obtain suitable survey respondents. As typical or average cases might not be the most informative or illustrative, case-study selection sought to identify information-rich cases. Flyvbjerg (2006:229), on the subject, further explains that "it is often more important to clarify the deeper causes behind a given problem and its consequences than to describe the symptoms of the problem and how frequently they occur. Random samples emphasizing representativeness will seldom be able to produce this kind of insight." This "information-oriented" selection process may seek to identify various types of cases, such as extreme, maximum variation, critical, or paradigmatic cases. For the purposes of this part of the research, it was important to identify particular types of initiatives for investigation.

Candidate initiatives were drawn from a review of current participation practice in RBM planning in Germany, the UK, and Ireland. Due to the implementation of the WFD, stakeholders are increasingly involved in RBM planning. The WFD distinguishes three levels of participation that are aimed at supporting the effective implementation of the directive: information, consultation, and "active involvement" (Art. 14). The related guidance document emphasizes that "active involvement" implies a higher degree of participation than information and consultation procedures provide and requires the continuous participation of stakeholders in the development and implementation of RBM plans (Working group 2.9 - Public Participation 2002). This study focused on these participatory platforms; candidate RBM initiatives were, therefore, required to meet the following criteria: 
- Suitable initiatives need to be inclusive and provide opportunity for interaction and extended engagement. These features are deemed essential in fostering social learning (e.g., Webler et al. 1995, Schusler et al. 2003) and were selected to limit the case studies to participatory efforts that could be assumed to demonstrate a process of social learning.

- The collaborative initiative should have a history of one or more years and average at least four meetings over the course of one year. The study intent here was to limit eligible initiatives to those that have had enough time for social learning to occur.

- Selected initiatives should vary in their degree of interaction, timeframe, age, etc. This prerequisite was selected to ensure that the final sample of collaborative initiatives included diverse participation designs that would allow for a comparative analysis between types of processes.

The search area was deliberately limited to Germany, the UK, and Ireland based on the language abilities of the researcher and already existing contacts with the respective authorities responsible for RBM. The Working Groups to support implementation of the WFD in the German state of SchleswigHolstein, hereafter referred to as "Working Groups," and the River Basin District (RBD) Advisory Councils in Ireland, hereafter referred to as "Advisory Councils," were selected for this investigation. A number of UK initiatives that were identified as suitable for this study could not be surveyed as we failed to obtain access to these groups.

The sample includes the stakeholders involved in the 34 Working Groups that were established at the catchment level to actively contribute to the RBM planning process in the German state of Schleswig Holstein. In Germany, RBM lies within the hands of the federal states, and in the state of Schleswig-Holstein, the three RBDs within or partly within the state territory were divided into 34 working areas. In each working area, usually covering a catchment or small river system, the state's environmental Ministry and highest water authority established a Working Group, consisting of up to ten members, including various interests. The second set of cases comprises the RBD Advisory Councils in the Republic of Ireland. Within each of the seven Irish RBDs, RBM planning falls within the responsibilities of the local authorities. In 2006, the coordinating authorities established seven RBD Advisory Councils to provide permanent fora for direct dialog and interaction between interested parties and the relevant authorities. Although both sets of cases were established within the same context (the WFD) and meet the specified selection criteria, which was confirmed by the responsible authorities, they differ considerably in how stakeholder interactions are organized (see Table 1).
Table 1. Characteristics of the cases investigated in the postal survey

\begin{tabular}{|c|c|c|}
\hline Initiative & $\begin{array}{l}\text { Working Groups } \\
\text { (Germany) }\end{array}$ & $\begin{array}{l}\text { RBD Advisory Councils } \\
\text { (Ireland) }\end{array}$ \\
\hline Cases & 34 & $7^{\dagger}$ \\
\hline Scale & Small sub-basins & RBD \\
\hline Membership & $\begin{array}{l}8 \text { to } 10 \text { members: Local } \\
\text { authorities, water user } \\
\text { associations, agriculture, } \\
\text { fisheries, local and regional } \\
\text { environmental NGOs, } \\
\text { regional water authorities. }\end{array}$ & $\begin{array}{l}\text { Varies between } 24 \text { to } 48 \\
\text { members: local authorities, } \\
\text { farming, environmental } \\
\text { NGOs, business and } \\
\text { industry, academia, } \\
\text { recreational users/fishing, } \\
\text { consumers. }\end{array}$ \\
\hline Purpose & $\begin{array}{l}\text { Working Groups support } \\
\text { local implementation of } \\
\text { WFD by examining \& } \\
\text { providing data; } \\
\text { development of local } \\
\text { measures. }\end{array}$ & $\begin{array}{l}\text { Advisory Councils support } \\
\text { responsible authority in the } \\
\text { preparation and } \\
\text { implementation of RBM } \\
\text { plans, e.g., the identification } \\
\text { of significant issues for } \\
\text { water management in the } \\
\text { respective RBDs. }\end{array}$ \\
\hline $\begin{array}{l}\text { Stage of } \\
\text { WFD cycle }\end{array}$ & $\begin{array}{l}\text { Identification of significant } \\
\text { water management issues }\end{array}$ & $\begin{array}{l}\text { Identification of significant } \\
\text { water management issues }\end{array}$ \\
\hline Methods & $\begin{array}{l}\text { Meetings are chaired by } \\
\text { member of the local water } \\
\text { and soil association; groups } \\
\text { examine, discuss, and } \\
\text { eventually amend planning } \\
\text { documents to be forwarded } \\
\text { to the authority responsible } \\
\text { for drafting RBM plans; } \\
\text { collective development of } \\
\text { local measures. }\end{array}$ & $\begin{array}{l}\text { Meetings are chaired by } \\
\text { staff of authority } \\
\text { responsible for drafting } \\
\text { RBM plans; presentations } \\
\text { are followed by plenary and } \\
\text { round table discussions; } \\
\text { occasional thematic } \\
\text { workshops. }\end{array}$ \\
\hline Timeline & $\begin{array}{l}\text { Since } 2002 \text {; bi-monthly or } \\
\text { monthly meetings. }\end{array}$ & $\begin{array}{l}\text { Since } 2006 \text {; four meetings a } \\
\text { year (on average). }\end{array}$ \\
\hline
\end{tabular}

${ }^{\dagger}$ Please note that only three out of seven Advisory Councils participated in the survey.

It should be noted that the purposive sampling method requires a degree of caution when drawing conclusions. Although the study does not provide a comprehensive description of social learning in all participatory initiatives currently operating in the context of RBM in Europe, the surveyed cases are certainly representative of two common types of stakeholder involvement and, in this sense, allow us to infer from the experiences made with these activities to other, similar types of participation. Moreover, this method does generate useful comparative data to draw some conclusions about the relationship between process characteristics and learning outcomes.

Data were collected using a self-administered questionnaire. To isolate questions, we followed a design procedure suggested by de Vaus (2002) where a phenomenon is first defined, then dimensions and sub-dimensions delineated, before identifying indicators, and finally, formulating 
Table 2. Description of process and outcome indicators investigated in this study

\begin{tabular}{|c|c|c|}
\hline \multicolumn{2}{|c|}{$\begin{array}{l}\text { Social learning conditions and } \\
\text { processes }\end{array}$} & (adapted from Webler et al. 1995, Schusler et al. 2003, Mostert et al. 2007) \\
\hline \multicolumn{2}{|l|}{ Inclusiveness } & All relevant views are represented in the process. \\
\hline \multicolumn{2}{|c|}{ Extended engagement } & The process provides opportunities for prolonged and frequent interaction. \\
\hline \multicolumn{2}{|c|}{ Opportunities for information exchange } & The process allows participants to exchange knowledge and information. \\
\hline \multicolumn{2}{|c|}{ Opportunities for dialog and interaction } & Participants should be able to engage in in-depth discussions and dialog. \\
\hline \multicolumn{2}{|l|}{ Process control } & The process allows participants to define the collaboration agenda and procedures. \\
\hline \multicolumn{2}{|l|}{ Open communication } & Participants openly share information and articulate and expose their views and interests. \\
\hline \multicolumn{2}{|l|}{ Equal participation } & Communication and interaction are characterized by equal participation by all parties involved. \\
\hline \multicolumn{2}{|c|}{ Social learning outcomes } & (adapted from Webler et al. 1995, Schusler et al. 2003, Röling. 2002, Mostert et al. 2007) \\
\hline \multirow[t]{2}{*}{$\begin{array}{l}\text { Relational }\{ \\
\text { change }\end{array}$} & Relationship building & Participants establish new relationships and develop a sense of community. \\
\hline & Trust building & Participants believe in the honesty and commitment of other group members. \\
\hline $\begin{array}{l}\text { Cognitive }\{ \\
\text { change }\end{array}$ & $\begin{array}{l}\text { Knowledge and } \\
\text { reflection }\end{array}$ & $\begin{array}{l}\text { Participants learn about and reflect on RBM, their understanding of the management problem at hand and that } \\
\text { of other group members. }\end{array}$ \\
\hline Agreement $^{\dagger}$ & $\begin{array}{l}\text { Developing common } \\
\text { views }\end{array}$ & Participants develop a shared understanding of the environmental situation. \\
\hline
\end{tabular}

${ }^{\dagger}$ The extent to which stakeholder groups developed a common view of the environmental situation at hand is used as an intermediate indicator for process outcomes.

questions. Literature suggests that social learning is thought to (1) occur in a participatory setting, (2) occur through a communicative process, (3) lead to a set of changes (social learning outcomes), and (4) contribute to a shared understanding and agreement among stakeholders (process outcomes). Each of these components can be further broken down into dimensions and sub-dimensions (Table 2). To illustrate, changes associated with social learning can be broadly grouped into the following dimensions: relational, cognitive, and technical changes (skills). Relational change can be further broken down into the following sub-dimensions: improved relationships and trust-building among stakeholders. For each dimension and sub-dimension, which were broadly grouped into process and outcome dimensions, indicators were derived from the literature. Twenty-five Likert-type statements were designed requesting responses on a four-point scale of agreement, ranging from strongly agree (1) to strongly disagree (4). A four- rather than a five-point scale, offering a distinct neutral point, was purposefully chosen to avoid respondents selecting this alternative (Czaja and Blair 2005). The survey instrument consisted mainly of closed questions but allowed respondents to provide comments at the end of the questionnaire. Questionnaire items were largely developed from instruments used in previous studies and extensively tested in a pilot study involving university students. Index reliability and internal consistency were tested using Cronbach's alpha statistic.

After access to the RBM initiatives was negotiated and approved by the responsible authorities, questionnaires were distributed to the 340 stakeholders involved in the Working
Groups in Schleswig-Holstein and the 117 stakeholders participating in the three Councils that had agreed to contribute to this study. Paper copies of the questionnaire, accompanied by a letter explaining the background to the study and a freepost return envelope, were disseminated by the Working Groups' chairs and the Advisory Councils' secretaries, respectively, in mid June 2007. A major difficulty in survey implementation was that questionnaire dissemination was facilitated by gatekeepers. As a result, non-respondents could not be specifically targeted. Potential inconsistencies in the dissemination and follow-up procedures may have impacted the responses received from the Advisory Councils. However, the low response rate may also be connected to poor attendance at Advisory Council meetings. Records, where available, show that, with the exception of one Council, attendance was low in the investigated councils. Two follow-up mailings were made following techniques suggested by Dillman (2007). Data collection was completed by October 2007.

Statistical analysis was performed using SPSS 10.0 for Windows. Scales were constructed from conceptually linked items to reduce the number of variables for subsequent analysis. Reliability of each composite measure was determined by computing Cronbach's alpha $(\alpha)$. The lower bound for scale reliability is commonly indicated at 0.70 (see Nunnaly 1978). However, a lower threshold of 0.60 is frequently used throughout the literature (Morgan and Griego 1998). All but the trust scale, which showed an inter-item correlation coefficient below .02 and was consequently excluded from the analysis, proved to be within the accepted boundaries of scale reliability with $\alpha$ between 0.69 and 0.80 . 
Subsequent statistical analysis mainly employed the MannWhitney-U-Test to identify significant differences in the responses between Working Group and Advisory Council survey participants (Siegel and Castellan 1988). For the analysis of the qualitative data, an inductive content analysis approach was adopted, meaning that the coding structure was developed and refined throughout the analytical process.

\section{RESULTS}

A total of 174 survey instruments were returned, yielding a response rate of $40 \%(n=130)$ from the German Working Groups and 38\% $(n=44)$ from the Irish Advisory Councils. Responses from the German sample represented 32 Working Groups, with the number of responses varying between one and six per group. The response rate per Advisory Council varied between $18(41 \%)$ from the Eastern, 13 (30\%) from the South-Eastern, and 8 (18\%) from the South-Western RBD Advisory Council. Five (11\%) respondents chose not to reveal their group membership. Because of this modest response rate, one should be careful in generalizing results to all members participating in the groups under each respective initiative.

Broken out by interest group (Table 3), representatives of the local authorities, environment, and nature conservation, as well as the water authorities and user associations, make up the majority of the German sample, together accounting for approximately $60 \%$ of respondents. Apart from the fishery $(13.8 \%)$ and farming sectors $(9.2 \%)$, responses by other interest groups were marginal. In the Advisory Council sample, the overwhelming majority of respondents represented the local authorities $(46.5 \%)$, followed by delegates from the environmental sector (18.6\%). Representatives of other interest groups only constitute a small share of the sample. Although response group characteristics seem somewhat unbalanced, it can be assumed that it is representative when we look at the membership structure of each type of initiative (see previous Section).

Reporting of results is divided into two sections: first, the two engagement initiatives are characterized in more detail based on official documents and meeting minutes as well as the perceptual data elicited from the respondents. Second, social learning and process outcomes are analyzed. The mean is used as a measure of central tendency and percentages are used instead of frequencies given the unequal sample sizes. Reporting of differences is based on the commonly accepted 0.01 significance level.

\section{Evaluation of the Learning Environment and Processes}

The Working Groups, which started their work in 2003, are managed by the water and soil associations, which were required to merge the existing nearly 500 associations into 34 new associations. Water and soil associations continue to exist, focusing on their traditional mandate of managing small rivers whereas the 34 newly established stakeholder groups exclusively focus on the implementation of the WFD within the remit of their respective work area. Depending on the specific tasks, Working Groups convene up to once a month but usually average five to six meetings a year (Ebell, unpublished manuscript).

Table 3. Frequency of responses by interest group

\begin{tabular}{lll}
\hline \hline Interest represented & Working Groups & Advisory Councils \\
\hline Local Authorities & $18.5 \%(24)$ & $46.5 \%(20)$ \\
$\begin{array}{l}\text { Environment and nature } \\
\text { conservation }\end{array}$ & $24.6 \%(32)$ & $18.6 \%(8)$ \\
$\begin{array}{l}\text { Water supply and waste } \\
\text { water treatment }\end{array}$ & $5.3 \%(7)$ & -- \\
Water authorities and user & $20.2 \%(26)$ & -- \\
associations & & \\
Fisheries & $13.8 \%(18)$ & $4.7 \%(2)$ \\
Farming & $9.2 \%(12)$ & $7.0 \%(3)$ \\
Business and industry & $2.3 \%(3)$ & $4.7 \%(2)$ \\
Tourism and recreation & -- & $4.7 \%(2)$ \\
Other & $3.8 \%(5)$ & $14.0 \%(6)$ \\
No response & $2.3 \%(3)$ & -- \\
Total responses & $40 \%(130)$ & $38 \%(44)$ \\
\hline
\end{tabular}

Since their inception, these groups have contributed to the characterization of rivers in Schleswig-Holstein and the development of monitoring programs in preparation for drafting the RBM plans. Data and documents provided by the Environmental Ministry, which is not represented in the Working Groups, are examined and discussed by the group and if necessary corrected or completed. Any recommendations, concerns, and suggestions are then communicated back to the Ministry by the group's chair, usually a representative of the water and soil associations, to be incorporated in the water management planning process (Rosenbaum, unpublished manuscript). Groups are expected to reach consensual decisions and to note any disagreements when forwarding their recommendations to the Ministry. A major aspect of their work is the development of the so-called "preliminary" measures, many of which have already been implemented to ensure that the objectives of the WFD (a good ecological status or potential by 2015) can be met in a timely fashion. These local measures, mainly focusing on the revitalization of rivers, require a consensus among all group members before detailed plans are drafted. Approved measures, which are funded by the Ministry, are usually implemented by the respective water and soil associations. In a publication in 2006, the Ministry, speaking of the groups' characterization of rivers, highlighted that, apart from few exemptions, most decisions were based on a consensus among group members (Ministerium für Landwirtschaft, Umwelt und ländliche Räume des Landes Schleswig-Holstein 2006).

In contrast, the Advisory Councils are managed by those local authorities that were appointed by the Ministry for Environment, Heritage and Local Government to coordinate the RBM planning process among the local authorities within 
Table 4. Respondents' assessment of the process characteristics broken out by initiative

\begin{tabular}{|c|c|c|c|c|c|}
\hline \multirow[b]{2}{*}{ Items } & \multicolumn{2}{|c|}{ Working Groups } & \multicolumn{2}{|c|}{ Advisory Councils } & \multirow{2}{*}{$\begin{array}{c}p \\
\text { value }^{\dagger}\end{array}$} \\
\hline & $\mathrm{N}$ & Mean $^{\dagger}$ & $\mathrm{N}$ & Mean & \\
\hline \multicolumn{6}{|l|}{ Inclusiveness } \\
\hline $\begin{array}{l}\text { Stakeholders fairly represent the sectors and interests, which are affected by } \\
\text { RBM planning. }\end{array}$ & 129 & $1.57(0.57)$ & 42 & $1.90(0.66)$ & 0.004 \\
\hline \multicolumn{6}{|l|}{ Extended engagement } \\
\hline $\begin{array}{l}\text { The length of the meetings is sufficient to enable participants to exchange } \\
\text { opinions and to discuss their interests, goals, and concerns }\end{array}$ & 129 & $1.39(0.63)$ & 42 & $2.07(0.87)$ & 0.000 \\
\hline $\begin{array}{l}\text { The number of the meetings is sufficient to enable participants to exchange } \\
\text { opinions and to discuss their interests, goals, and concerns. }\end{array}$ & 130 & $1.37(0.57)$ & 44 & $2.14(0.73)$ & 0.000 \\
\hline \multicolumn{6}{|l|}{ Opportunities for information exchange } \\
\hline $\begin{array}{l}\text { The methods employed during the meetings provide the stakeholders with } \\
\text { the opportunity to obtain and provide information. }\end{array}$ & 130 & $1.49(0.61)$ & 43 & $2.09(0.71)$ & 0.000 \\
\hline \multicolumn{6}{|l|}{ Opportunities for dialog and interaction } \\
\hline $\begin{array}{l}\text { The methods employed during the meetings provide the stakeholders with } \\
\text { the opportunity to discuss their interests, goals, and concerns. } \\
\text { Process control }\end{array}$ & 130 & $1.62(0.72)$ & 43 & $2.16(0.90)$ & 0.000 \\
\hline I have influence on the selection of agenda items. & 128 & $1.88(0.91)$ & 42 & $2.45(0.77)$ & 0.000 \\
\hline $\begin{array}{l}\text { I have influence on the way meetings are run and on the communication and } \\
\text { interaction methods that are employed. }\end{array}$ & 127 & $2.13(0.88)$ & 41 & $2.56(0.78)$ & 0.008 \\
\hline \multicolumn{6}{|l|}{ Open communication } \\
\hline I believe that participants openly share knowledge and information. & 128 & $1.59(0.63)$ & 42 & $2.02(0.78)$ & 0.001 \\
\hline I believe that participants openly share their concerns, interests, and goals. & 127 & $1.63(0.64)$ & 44 & $1.98(0.66)$ & 0.003 \\
\hline I feel comfortable expressing my opinion. & 128 & $1.26(0.56)$ & 41 & $1.66(0.62)$ & 0.000 \\
\hline $\begin{array}{l}\text { I also express my ideas when they differ from the ones expressed by other } \\
\text { participants. }\end{array}$ & 128 & $1.23(0.43)$ & 41 & $1.71(0.68)$ & 0.000 \\
\hline \multicolumn{6}{|l|}{ Equal participation } \\
\hline I am satisfied with the amount of influence I have in the group meetings. & 127 & $1.66(0.66)$ & 39 & $2.38(0.85)$ & 0.000 \\
\hline My views and concerns are treated seriously by other participants. & 128 & $1.52(0.57)$ & 41 & $2.15(0.69)$ & 0.000 \\
\hline
\end{tabular}

${ }^{\dagger}$ Means based on four-point response scale, ranging from $1=$ strongly agree to $4=$ strongly disagree, standard deviation in brackets; ${ }^{\dagger}$ Significant at $p<0.01$.

the respective RBDs. For each Council, the local authorities appointed two delegates who then co-opted additional members to represent community and sectoral interests. The number of co-opted members equals at least $50 \%$ of the number of persons appointed by local authorities but never exceeds this number. The size of the councils, therefore, depends on the amount of local authorities within a RBD and the number of co-opted representatives, thus varying between 24 and 48 members in the surveyed Councils (Department of the Environment, Heritage and Local Government, 2005). Under the European Communities (Water Policy) (Amendment) Regulations 2005, councils are required to meet at least twice a year, and although there are some variations, most Councils convene on average four times a year. The main purpose of the Advisory Councils is to advise the relevant public authorities and make recommendations on the preparation of RBM plans. Since their inception in 2006, stakeholders have been mainly concerned with the development of the monitoring program, which was put in place after the initial characterization of the RBDs. At the time of survey implementation, stakeholder groups under both initiatives had just completed working on and contributing to the identification of the significant water management issues in their respective (sub)basins.
To obtain an accurate description of the two approaches we cannot simply rely on factual data but need to take into account the observations and experiences of the participants. The survey questionnaire assessed the following process characteristics, which are assumed to be key to encouraging social learning among stakeholders: inclusiveness, extended engagement, opportunities for information exchange and interaction, process control, open communication, and equal participation. Table 4 shows mean scores and significant differences between the two response groups for each item assessing the quality of the learning environment and processes of the respective initiative; mean scores for aggregate measures are illustrated in Fig. 2.

\section{Inclusiveness}

The majority of German respondents assess the Working Groups as inclusive (96\%), with responses almost evenly split between the two response categories, indicating agreement with the questionnaire item (Mean 1.57, SD 0.57). In comparison, agreement-although accounting for $82 \%$ of responses-is significantly $(p<0.01)$ lower among Advisory Council members (Mean 1.90, SD 0.66). This is somewhat surprising considering that Advisory Councils involve a diverse set of interest groups, including farming, businesses, 
academia, environmental NGOs, and consumers. The membership structure is, therefore, not fundamentally different from that of the Working Groups. This might be explained by the poor record of attendance in the surveyed councils, which was raised by a number of Advisory Councils in their comments. Although half of the commentators interpreted this as a lack of commitment, the remaining statements linked the frequent absence of certain interest groups to a lack of funding. It needs to be understood that the Advisory Councils cover RBDs, which vary between 6,263 $\mathrm{km}^{2}$ and $15,000 \mathrm{~km}^{2}$. Therefore, depending on where meetings are held, attending these meetings incurs considerable travel costs for some of the members.

Fig. 2. Respondents' aggregate assessment of the process characteristics broken out by initiative

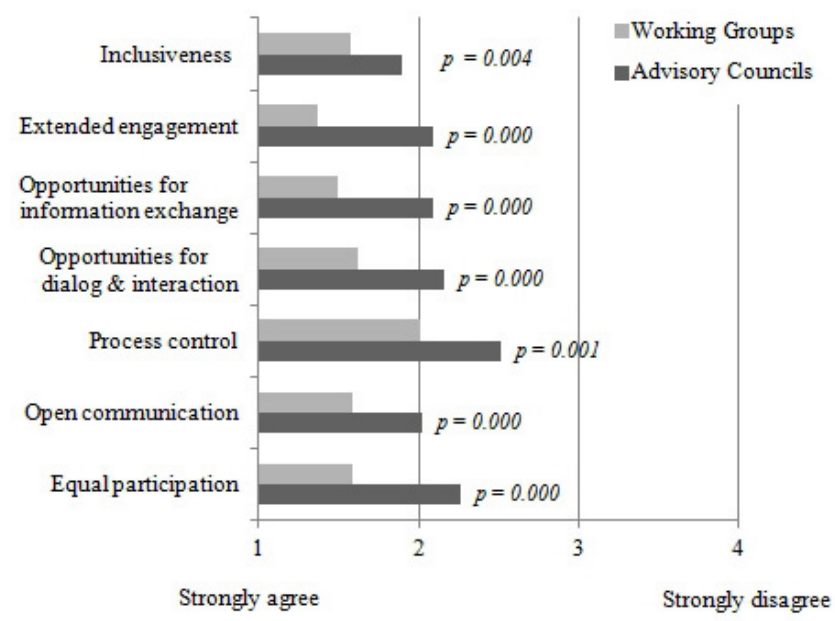

Extended engagement

As expected, Advisory Council participants, who only meet every 3 months on average, rate the overall time frame as less favorable than the Working Group members with a mean score of 2.09 (SD 0.70). Nevertheless, $69 \%$ assessed the length of meetings and $76.7 \%$ the number of meetings as sufficient to facilitate information exchange and discussions among stakeholders. The data suggest that the overall time frame of the Working Groups was successful in providing these opportunities with a mean assessment score of 1.37 (SD 0.53) for the scaled items. Disaggregated, over $90 \%$ of German respondents indicated agreement with the two component statements of the scale. However, although the overall time frame of the Advisory Councils seems to provide significantly less time for engagement $(p<0.01)$ than the Working Groups, one should note that the overall assessment is still rather positive.

Opportunities for information exchange and dialog

When we look at how respondents assess the opportunities for information exchange and interaction, we notice that, again, agreement with both items is significantly lower among respondents from the Advisory Council than the German respondents at the $p<0.01$ level. German respondents feel that Working Groups provide them with the opportunity exchange information (94\%) and to a slightly lesser degree to discuss their interests and concerns with other group members (89\%). A similar response pattern can be seen when looking at the data from the Advisory Councils, where three-quarters of respondents agree that Council meetings facilitate information exchange $(77 \%)$ and $70 \%$ consider the Council meetings allow for deliberation among participants. Comments made stressed that participants felt overburdened with the amount of time required to examine the voluminous data provided by the Environmental Ministry. It was indicated that, particularly representatives outside of the water sectoroften voluntary representatives-were challenged by the workload and the complexity of the subject matter.

\section{Process control}

Given the rather autonomous structure of the Working Groups, it is a little surprising that the German respondents rated their ability to influence how stakeholders cooperate and determine the issues they address significantly higher (Mean 2.01, SD 0.80) than the Advisory Council members (Mean 2.51, SD 0.68 ) with $p<0.01$. In comparison, Irish respondents consider themselves to be less influential with respect to agenda setting, with around two-thirds indicating agreement (64\%) and just over half of respondents agreeing that they can influence the process design (48\%). However, on close inspection, it seems that Working Group members exercise less process control than expected: three-quarters felt they had some influence on selecting agenda items (74\%), and 64\% thought they could influence the way meetings were run or the selection of methods. In a number of comments, respondents alluded to the rather stringent procedures groups are expected to adhere to by the Ministry and which ultimately constrain the stakeholders' discussions and subsequent decisions. In this context, frequent mention is also made of the complexity and amount of data stakeholders are provided with to examine, which respondents feel challenges many of the (non-water related) representatives, thus limiting in-depth discussions.

Open communication and equal participation

The composite measures suggest that stakeholder communication among Working Group members was characterized by a high degree of openness. In comparison, Advisory Council members are perceived to be significantly less willing to share knowledge and expose their views $(p<$ $0.01)$. The data suggest that communication among Working Group members was well balanced, whereas Advisory Council members assessed stakeholder communication among the members to be significantly less equitable ( $p<$ $0.01)$. These items generated a relatively high percentage of disagreement compared to the survey items described so far. 
Table 5. Indicators of relational and cognitive change as well as agreement broken out by initiative

\begin{tabular}{|c|c|c|c|c|c|}
\hline \multirow[b]{2}{*}{ Items } & \multicolumn{2}{|c|}{ Working Groups } & \multicolumn{2}{|c|}{ Advisory Councils } & \multirow{2}{*}{$\begin{array}{r}p \\
\text { value }^{\dagger \dagger}\end{array}$} \\
\hline & $\mathrm{N}$ & Mean $^{\dagger}$ & $\mathrm{N}$ & Mean $^{\dagger}$ & \\
\hline \multicolumn{6}{|l|}{ Relational change } \\
\hline $\begin{array}{l}\text { As a result of the involvement process, I have better working relationships with the } \\
\text { other participants. }\end{array}$ & 123 & $1.68(0.70)$ & 39 & $2.00(0.61)$ & 0.006 \\
\hline $\begin{array}{l}\text { As a result of the involvement process, I feel part of a group trying to solve a } \\
\text { common problem. }\end{array}$ & 129 & $1.60(0.72)$ & 42 & $1.98(0.75)$ & 0.002 \\
\hline $\begin{array}{l}\text { I would be happy to work again with the same participants in a similar involvement } \\
\text { process. }\end{array}$ & 129 & $1.54(0.69)$ & 43 & $1.79(0.74)$ & 0.036 \\
\hline \multicolumn{6}{|l|}{ Cognitive change } \\
\hline $\begin{array}{l}\text { As a result of the involvement process, I have a better understanding of water } \\
\text { resources and RBM. }\end{array}$ & 127 & $1.47(0.70)$ & 44 & $1.48(0.63)$ & 0.736 \\
\hline $\begin{array}{l}\text { As a result of the involvement process, I have a better understanding of the concerns } \\
\text { and interests of other participants. }\end{array}$ & 127 & $1.64(0.66)$ & 44 & $1.66(0.64)$ & 0.799 \\
\hline $\begin{array}{l}\text { As a result of the process, I altered my views about important issues and problems } \\
\text { for water resources and RBM. } \\
\text { Agreement }\end{array}$ & 128 & $2.37(0.94)$ & 43 & $2.49(1.03)$ & 0.567 \\
\hline $\begin{array}{l}\text { The involvement process contributed to the development of a common view among } \\
\text { the participants of the current status of the RBD as well as immediate problems and } \\
\text { their causes. }\end{array}$ & 126 & $1.75(0.73)$ & 35 & $2.34(0.87)$ & 0.000 \\
\hline
\end{tabular}

${ }^{\dagger}$ Means based on four-point response scale, ranging from $1=$ strongly agree to $4=$ strongly disagree, standard deviation in brackets; ${ }^{\dagger}$ Significant at $p<0.01$.

\section{Analysis of Social-Learning Outcomes}

Table 5 shows mean scores and significant differences between the two response groups for each item assessing the indicators used to measure changes in group relations, cognitive change, and agreement reached; mean scores for aggregate measures are illustrated in Fig. 3.

Fig. 3. Aggregate measures of relational and cognitive change as well as agreement broken out by initiative

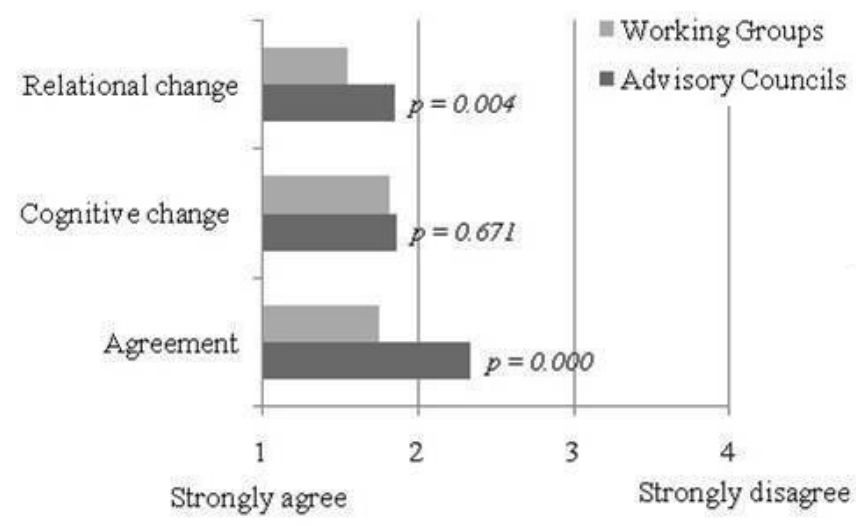

\section{Relational change}

The mean response score of the scaled items indicates that relationship building was significantly stronger among Working Group members than among respondents from the
Advisory Councils $(p<0.01)$. Of the German respondents, $83 \%$ reported to have improved working relationships, $89 \%$ claimed to have developed a sense of community, and $89 \%$ stated they were happy to collaborate again with the same group of people. Response frequencies for the Advisory Council members were $77 \%, 75 \%$, and $84 \%$ for the respective items.

\section{Cognitive change}

The reported cognitive changes are of similar magnitude when we compare responses across groups, with a mean response score of 1.82 (SD 0.61) for study participants from the Working Groups and 1.86 (SD 0.60) from Advisory Council members for the composite measure. When we look at the individual items, we see that assessment scores for each component are in a similar range: $88 \%$ of Working Group respondents and $93 \%$ of Advisory Council respondents report having developed a better understanding of water management issues and RBM through their involvement. The majority of respondents from both samples ( $88 \%$ and $90.9 \%$ ) feel more knowledgeable about other participants' interests and concerns. In comparison, fewer respondents from both groups altered their views about important issues and problems for water resources and RBM as a result of the stakeholder activities. In both groups, just over half of the respondents$51 \%$ of Working Groups and 52\% of Advisory Council respondents-reported that they have adapted their views. These are the only items where responses indicating agreement and disagreement are approximately balanced in both groups 
and where responses, when compared, are not significantly different.

\section{Agreement}

At the time of survey implementation, stakeholders under both initiatives had just completed working on and contributing to the identification of significant water management issues for their respective river basins and catchments. The majority of the Working Group members, namely $86 \%$, felt that the engagement activity had contributed to the development of a common view among the participants regarding the current status of the RBD as well as immediate problems and their causes. Only about half of the Advisory Council respondents $(55 \%)$ and thus a significantly lower proportion than in the German sample report the development of a shared understanding $(p<0.01)$. Readers should note that the survey instrument included questions about the quality of the group decision-making process and the level of consensus achieved. However, due to a large proportion of missing values, we decided not to include the data in this paper.

\section{DISCUSSION}

We begin this discussion by characterizing each participatory initiative based on the elicited perceptual data, before examining the evidence for social learning. On paper, the two investigated participation initiatives met the process requirements that are considered central to social learning in the literature. Both involve a diverse set of stakeholders, who frequently meet over a prolonged period of time to obtain, provide, and exchange information and to discuss their needs, concerns, and ambitions (Webler et al. 1995, Schusler et al. 2003, Mostert et al. 2007). Yet, as we illustrated above, they differ considerably in how stakeholder interactions were organized, particularly the time frame, group size, and prevailing mode of communication.

Survey results highlight the consistently and significantly more positive assessment of the process characteristics by the Working Groups when compared with that of the Advisory Council responses. However, one should be careful in interpreting these results as suggesting that the Advisory Council is not meeting any of the process criteria assessed. The data merely indicate that the Advisory Councils provide comparatively fewer opportunities for extended engagement, information exchange, and interaction than the Working Groups. Although we need to concede that these interpretations are largely based on the perceptual data elicited from the respondents, they point at the prominent role structural features and process management play in the quality of stakeholder communication and interaction (Beierle and Konisky 1999, Halvorsen 2001).

Given these differences in the extent to which both initiatives create more or less "ideal" learning opportunities, if we follow the propositions made in the literature, it is not surprising that the Working Group respondents register significantly stronger relational changes than the Advisory Council members. Interestingly, however, cognitive change is equally strong in both groups. Participants of both groups indicated a strong increase in their general knowledge about water and RBM as well as about the interests and concerns of other stakeholders, thus corresponding with results reported in other studies on social learning (e.g., Webler et al. 1995, Schusler et al. 2003) and participation in general (e.g., Leach et al. 2002, Frame et al. 2004). In contrast, instances of changed perceptions, assumed to be crucial for the development of a shared understanding of the environmental situation at hand, are comparatively rarer in both studied groups.

To return to one of the key questions guiding this research, we might ask what these findings tell us about the capacity of stakeholder platforms to transform relationships and stakeholder thinking, both key elements of the social-learning model described by the literature. First, to fully understand relational phenomena, we have to acknowledge that they do not reside in a person, but rather in interactions between individuals and groups. Thus, they are inherently dynamic and time dependent (Cooper and Skaggs Sheldon 2002). Rist et al. (2006) conclude that different features of social-learning processes tend to occur simultaneously; their prominence, however, varying depending on the phase of the stakeholder activity. Survey findings show that the more mature Working Groups record comparatively stronger relational changes than the Advisory Councils, confirming results reported by Leach et al. (2002). Based on a survey of 44 watershed groups, the authors convincingly argue that effects on the social and human capital gradually increase as partnerships age. In contrast and perhaps most surprisingly, both groups report equally strong cognitive changes; respondents are particularly positive about their improved understanding of water resources and RBM as well as the concerns and interests of other group members. Yet, as the data suggest, only few stakeholders seem to have integrated this information into their own perspective resulting in a changed understanding of the environmental situation. Even participants in the Working Groups, despite having a considerably longer history, report having gained many new insights but concede they have not altered their general views on the problem at hand.

Armitage et al. (2008:12) point out that "Learning at times can be quite superficial and less meaningful than expected." This is not to say that the learning experienced by the stakeholders is irrelevant or even undesirable, but we need to acknowledge that there are different types of learning or change. Learning involves an element of acquisition or accumulation, e.g., of knowledge or skills, as well as of transformation, e.g., of views, perceptions, and emotions (see also Webler et al. (1995)). Findings suggest that the observed processes of social learning mainly involved the first and in fewer instances the second. Considering that just half of the surveyed members of 
the comparatively more "ideal" and mature Working Groups recorded transformational change, we can conclude that some things may be "harder to learn" than others. We should, however, not ignore that these results may also reflect a lack of awareness of any changes having taken place or even an unwillingness to report any changes of opinion as they might be equated to admitting one was wrong before. Conversely, results may be artificially inflated through cognitive dissonance (see Festinger 1957). Coglianese (2002) explains that stakeholders may subconsciously overestimate their partnership's achievements to avoid the emotional discomfort produced by discrepancies between the initiative's stated objectives and its actual effects.

The comparatively stronger evidence of social learning among Working Group respondents suggests that their organizational features might be more appropriate in ensuring the communicative process assumed to facilitate social learning than the organizational shape of the Advisory Councils. The Working Group model provides more time for the engagement process, and the overall arrangement allows group members to actively engage with one another as well as the subject matter. However, although these findings corroborate results of previous studies (Schusler et al. 2003, Mostert et al. 2007), one should be cautious in attributing this success solely to the organizational shape. Our study only provides a snapshot of a social process the quality and outcomes of which are likely to change and evolve over time (Rist et al. 2006).

Furthermore, the investigation revealed the considerable investments, both in terms of time and costs, that stakeholders are required to make in order to actively participate in these intense and prolonged involvement efforts. In contrast to the Working Groups, Advisory Council meetings were poorly attended, which is thought to be a function of the scale at which they were established. The large area covered by each RBD Advisory Council incurs considerable travel costs for council members, specifically burdening the budgets of the NGO delegates. Working Group members, on the other hand, frequently mentioned feeling overburdened, both in terms of time commitment as well as the complexity of the subject matter. We cannot draw any conclusions as to whether and how these (personal) costs might have impeded sociallearning processes in the investigated cases but they do highlight the real danger of participants withdrawing from learning-oriented engagement activities (cf. Rist et al. 2007).

\section{CONCLUSIONS}

Social learning is increasingly cited as an essential element of and motivation for participatory NRM. Based on results of a postal survey of stakeholder experiences in two involvement initiatives, we can draw two main conclusions: (1) social learning is a multi-dimensional and dynamic process and (2) the extent to which stakeholder platforms promote social learning is shaped by organizational arrangements and time provided for the engagement process.
Findings show that, although stakeholders readily acquire knowledge and improve relationships, the transformation of views and the development of a shared group identity are outcomes that are harder to achieve. Even more advanced engagement processes, such as the surveyed Working Groups, seem to be limited in their ability to arrive at those cognitive changes considered to be a prerequisite for merging stakeholder perceptions into collectively held views and shared understandings, often seen as a first step toward consensus building and collective action. Although many authors acknowledge that the changes attributed to social learning affect a number of different dimensions, i.e., result in multiple learning outcomes (e.g., Webler et al. 1995, Schusler et al. 2003), only few recognize that these changes might occur at different stages of a stakeholder learning process (Rist et al. 2006). This study clearly indicates that social learning is a multi-dimensional and dynamic process and, as such, breadth (types of change, including social, cognitive, and technical change) and depth (intensity of change, including acquisition of knowledge to transformation of views) of learning will change and evolve as engagement activities unfold. Given that relational phenomena are inherently dynamic, researchers, river basin managers and participation practitioners are encouraged to monitor stakeholder activities over a prolonged period of time to develop a better understanding of the temporal structure of learning processes.

Corresponding to earlier research findings, more interactive and dialogical types of processes seem to be more promising in facilitating social learning than engagement activities only allowing for two-way communication between stakeholders and responsible authorities. However, following on from the point just made, findings also imply that specific sociallearning outcomes might be achievable through less intense stakeholder activities, both in terms of time and interaction, seeing that the surveyed initiatives resulted in relatively high levels of aspects of cognitive change.

However, one should be cautious in attributing this success solely to the organizational arrangements. Due to shortcomings in the collected data sets, this study was clearly limited in its ability to demonstrate the comparative benefits of different types of participation processes for social learning and, more specifically, to identify process characteristics that are conducive to stakeholder learning; only a limited number of cases provided sample sizes that would allow us to generate aggregate measures per case, a type-wise comparison provided the best and most suitable alternative for drawing some conclusions about the relationship between social learning and process type. Ideally, a larger number of individual cases should be investigated to enable the disaggregation of results by case to identify factors that explain differences in outcomes and to derive key lessons to inform and develop new models for participation practice. Furthermore, it should be noted that, although all cases were about the WFD, specific problems or 
even cultural contexts were not taken into consideration. Contexts may differ, for instance, with regard to the experience with participatory processes and the public awareness of the urgency of the water management issue. Moreover, this study focused on specific components of social learning and its preconditions. One could argue that not only the arrangement but also the substance of the process, particularly the degree of conflict or tension between parties, plays a role (Mostert et al. 2007). Although all cases were set in a specific context, the WFD, the landscape of problems and issues to be addressed might vary.

Finally, some practical lessons can be drawn from the study. First, responsible authorities, water managers, and stakeholders should approach involvement processes with the right level of expectations and acknowledge that, even in a highly interactive forum such as the Working Groups, social learning might occur to a lesser extent than expected or desired. Conversely, practitioners need to realize that certain ambitions might be achievable through lower intensity involvement activities, as demonstrated by the Advisory Councils. Secondly, and following on from the previous point, considering that the initiative that demonstrated the highest degree of learning among stakeholders in this study, the Working Groups, demanded a high level of commitment and, probably, resources, we need to acknowledge that it requires extended engagement, potentially years, to achieve the benefits associated with social learning. Responsible authorities should be aware of the considerable financial and time commitments and the difficult task of ensuring continuous stakeholder commitment. Against this background, careful consideration should be given to the question of which issues are critically in need of or appropriate for a learning approach. In some cases, where urgent solutions are required or issues are highly contested, an intense and prolonged engagement initiative might not be feasible or appropriate. By the same token, identifying the type of learning outcomes most relevant for their specific situation may prevent practitioners from designing unnecessarily long and intense stakeholder processes.

Responses to this article can be read online at: http://www.ecologyandsociety.org/voll7/iss 1/art3/responses/

\section{Acknowledgments:}

This research was funded by the European Commission under contract \# 511231-2.

\section{LITERATURE CITED}

Abelson, J., P. G. Forest, J. Eyles, P. Smith, E. Martin, and F. P. Gauvin. 2003. Deliberations about deliberation: issues in the design and evaluation of public consultation processes.
Social Science and Medicine 57:239-251 http://dx.doi.org/10 .1016/S0277-9536(02)00343-X

Argyris, C., and D. Schön. 1978 Organizational learning. Addison-Wesley, Reading, Massachusetts, USA.

Armitage, D., M. Marschke, and R. Plummer. 2008. Adaptive co-management and the paradox of learning. Global Environmental Change 18(1):86-98. http://dx.doi.org/10.1016/ j.gloenvcha.2007.07.002

Babbie, E. R. 2001. The practice of social research. Ninth edition. Wadsworth, Belmont, California, USA.

Bandura, A. 1977. Social learning theory. Prentice-Hall, Englewood Cliffs, New Jersey, USA. http://dx.doi.org/10.1111/ j.1460-2466.1978.tb01621.x

Bandura, A. 1986. Social foundations of thought and action: a social cognitive theory. Prentice Hall, Englewood Cliffs, New Jersey, USA.

Beierle, T. C., and D. M. Konisky. 1999. Public participation in environmental planning in the Great Lakes region. Discussion paper 99-50. Resources for the Future, Washington, D.C., USA. [online]. URL: http://www.rff.org/rff/ Publications/Discussion Papers.cfm.

Beierle, T., and J. Cayford. 2002. Democracy in practice. Public participation in environmental decision. Resources for the Future, Washington, D.C., USA.

Buchy, M., and S. Hoverman. 2000. Understanding public participation in forest planning: a review. Forest Policy and Economics 1:15-25. http://dx.doi.org/10.1016/S1389-9341(00) $\underline{00006-X}$

Carr, D. S., and K. E. Halvorsen. 2001. An evaluation of three democratic, community-based approaches to citizen participation: surveys, conversations with community groups, and community dinners. Society and Natural Resources 14:107-126. http://dx.doi.org/10.1080/089419201300000526

Coglianese, C. 2002. Is satisfaction success? Evaluating public participation in regulatory policy making. Faculty Research Working Papers Series RWP02-038. John F. Kennedy School of Government, Harvard University, Cambridge, Massachusetts, USA. [online]. URL: $\underline{\text { http://paper }}$ s.ssrn.com/abstract=331420.

Cooper, L., and M. Skaggs Sheldon. 2002. Seventy years of research on personality and close relationships: substantive and methodological trends over time. Journal of Personality 70(6):783-812. http://dx.doi.org/10.1111/1467-6494.05024

Cundill, G. 2010. Monitoring social learning processes in adaptive comanagement: three case studies from South Africa. 
Ecology and Society 15(3): 28. [online] URL: http://www.eco logyandsociety.org/vol15/iss3/art28/.

Czaja, R., and J. Blair. 2005. Designing surveys: a guide to decisions and procedures. Second edition. Sage, Thousand Oaks, California, USA.

Department of the Environment, Heritage and Local Government. 2005. Water matters: guidelines for the establishment of River Basin District Advisory Councils (RBDAC). Department of the Environment, Heritage and Local Government, Custom House, Dublin, Ireland. [online]. URL: http://www.wfdireland.ie/Documents/RBDACs/Guidelines\% 20\%20for\%20est $\% 20$ of $\% 20$ RBDACs $\% 20-\% 20 \% 2016 \% 2008 \%$ 2005.pdf.

De Vaus, D. A. 2002. Surveys in social research. Fifth edition. Routledge, London, UK.

Dillman, D. A. 2007. Mail and internet surveys: the tailored design method 2007 update with new internet, visual, and mixed-mode guide. Second edition. Wiley, Hoboken, New Jersey, USA.

Festinger, L. 1957. A theory of cognitive dissonance. Stanford University Press, Stanford, Connecticut, USA.

Flyvbjerg, B. 2006. Five misunderstandings about case-study research. Qualitative Inquiry 12(2):219-245. http://dx.doi.org $\underline{10.1177 / 1077800405284363}$

Frame, T. M., T. Gunton, and J. C. Day. 2004. The role of collaboration in environmental management: an evaluation of land and water resource planning in British Columbia. Journal of Environmental Planning and Management 47(1):59-82. http://dx.doi.org/10.1080/0964056042000189808

Garmendia, E., and S. Stagl. 2010. Public participation for sustainability and social learning: concepts and lessons from three case studies in Europe. Ecological Economics 69 (8):1712-1722. http://dx.doi.org/10.1016/j.ecolecon.2010.03.027

Gleick, P. H. 2003. Global freshwater resources: soft-path solutions for the 21st century. Science 203:1524-1528. http:// dx.doi.org/10.1126/science.1089967

Habermas, J. 1987 The theory of communicative action. Vol. 2. Lifeworld and system. A critique of functionalist reason. Beacon Press, Boston, Massachusetts, USA.

Halvorsen, K. E. 2001. Assessing public participation techniques for comfort, convenience, satisfaction, and deliberation. Environmental Management 28(2):179-186. http://dx.doi.org/10.1007/s002670010216

Ison, R., N. Röling, and D. Watson. 2007. Challenges to science and society in the sustainable management and use of water: Instigating the role of social learning. Environmental Science and Policy 10(6):499-511. http://dx.doi.org/10.1016/ j.envsci.2007.02.008
Kessler, B. L. 2004. Stakeholder participation: a synthesis of current literature. National Marine Protected Areas Center, in cooperation with the National Oceanic and Atmospheric Administration Coastal Services Center, Silver Spring, Maryland, USA. [online]. URL: http://www.mpa.gov/pdf/pub lications/Stakeholder Synthesis.pdf.

Knowles, M. S., E. F. Holton, and R. A. Swanson. 2005. The adult learner: the definitive classic in adult education and human resource development. Sixth edition. Elsevier, Burlington, Massachusetts, USA.

Kolb, D. A. 1984. Experiential learning: experience as the source of learning and development. Prentice-Hall, Englewood Cliffs, New Jersey, USA.

Lave, J., and E. Wenger. 1991. Situated learning. Legitimate peripheral participation. University of Cambridge Press, Cambridge, UK. http://dx.doi.org/10.1037/10096-003

Leach, W. D., N. W. Pelkey, and P. Sabatier. 2002. Stakeholder partnerships as collaborative policy making: evaluation criteria applied to watershed management in California and Washington. Journal of Policy Analysis and Management 21(4):645-670. http://dx.doi.org/10.1002/pam.1 $\underline{0079}$

Leeuwis, C. 2000 Reconceptualizing participation for sustainable rural development: towards a negotiation approach. Development and Change 31:931-959. http://dx.do i.org/10.1111/1467-7660.00184

Loeber, A. 2003. Learning processes at group level. Pages 8399 in J. Cramer, editor. Learning about corporate social responsibility - the Dutch experience. IOS Press, Amsterdam, THe Netherlands.

Ministerium für Landwirtschaft, Umwelt und ländliche Räume des Landes Schleswig-Holstein (MLUIRLSH). 2006. Infobrief zur EU Wasserrahmenrichtlinie. 1/2006. MLUIRLSH, Kiel, Germany.[online]. URL: http://www.wasser.sh/de/fachi nformation/daten/nps/infobriefe/infobrief 01-2006.pdf.

Morgan, G. A., and O. V. Griego. 1998. Easy use and interpretation of SPSS for Windows: answering research questions with statistics. Lawrence Erlbaum Associates, Mahwah, New Jersey, USA.

Mostert, E., C. Pahl-Wostl, Y. Rees, B. Searle, D. Tabara, and J. Tippett. 2007. Social learning in European river-basin management: barriers and fostering mechanisms from 10 river basins. Ecology and Society 12(1). [online] URL: http://www. ecologyandsociety.org/vol12/iss1/art19/.

Muro, M., and P. Jeffrey. 2008. A critical review of the theory and application of social learning in participatory natural resource management processes. Journal of Environmental Planning and Management 5(3):325-344. http://dx.doi.org/1 $\underline{0.1080 / 09640560801977190}$ 
Nunnaly, J. 1978. Psychometric theory. McGraw-Hill, New York, New York, USA. http://dx.doi.org/10.2307/1175619

Pahl-Wostl, C. 2002. Towards sustainability in the water sector: the importance of human actors and processes of social learning. Aquatic Science 64: 394-411. http://dx.doi.org/10.1 $\underline{007 / P L 00012594}$

Pahl-Wostl, C. 2006. The importance of social learning in restoring the multifunctionality of rivers and floodplains. Ecology and Society 11(1):10. [online]. URL: http://www.eco logyandsociety.org/vol11/iss1/art10/.

Reed, M. S., A. C. Evelz, G. Cundill, I. Fazey, J. Glass, A. Laing, J. Newig, B. Parrish, C. Prell, C. Razmond, and L. C. Stringer. 2010. What is social learning. Ecology and Society 15(4): r1. [online] URL: http://www.ecologyandsociety.org/vol15/ iss4/resp1/. http://dx.doi.org/10.1109/TCAC.1989.697087

Rist, S., M. Chiddambaranathan, C. Escobar, and U. Wiesemann. 2006. "It was hard to come to mutual understanding ..."-the multidimensionality of social learning processes concerned with natural resource use in India, Africa and Latin America. System Practice Action Research 19 (3):219-237. http://dx.doi.org/10.1007/s11213-006-9014-8

Rist, S., M. Chiddambaranathan, C. Escobar, U. Wiesemann, and A. Zimmermann. 2007. Moving from sustainable management to sustainable governance of natural resources: the role of social learning processes in rural India, Bolivia and Mali. Journal of Rural Studies 23(1):219-237. http://dx.doi.o rg/10.1016/j.jrurstud.2006.02.006

Röling, N. 2002. Beyond the aggregation of individual preferences. Pages 25-48 in C. Leeuwis and R. Pyburn, editors. Wheelbarrows full of frogs. Social learning in rural resource management. Koninklijke Van Gorcum, Aasen, The Netherlands.

Rowe, G., and L. Frewer. 2000. Public participation methods: a framework for evaluation. Science, Technology, and Human Values 25(1):3-29. http://dx.doi.org/10.1177/016224390002500101

Schuett, M. A., S. W. Selin, and D. S. Carr. 2001. Making it work: keys to successful collaboration in natural resource management. Environmental Management 27 (4):587-593. http://dx.doi.org/10.1007/s002670010172

Schusler, T. M., D. J. Decker, and M. J. Pfeffer. 2003. Social learning for collaborative natural resource management. Society and Natural Resources 15:309-326. http://dx.doi.org /10.1080/08941920390178874

Siegel, S., and J. Castellan. 1988. Nonparametric statistics for the behavioral sciences. Second edition. McGraw-Hill, New York, New York, USA. http://dx.doi.org/10.1086/416341
Steyaert, P., and J. Jiggins. 2007. Governance of complex environmental situations through social learning: a sysnthesis of SLIM's lessons for research, policy and practice. Environmental Science and Policy 10(6):575-586. http://dx.d oi.org/10.1016/j.envsci.2007.01.011

Webler, T., H. Kastenholz, and O. Renn. 1995. Public participation in impact assessment: a social learning perspective. Environmental Impact Assessment Review 1 (5):443-463. http://dx.doi.org/10.1016/0195-9255(95)00043E

Webler, T., S. Tuler, and R. Krueger. 2001. What is a good public participation process? Five perspectives from the public. Environmental Management 27(3):435-450. http://dx. doi.org/10.1007/s002670010160

Williams, M. E., and P. V. Ellefson. 1996. Natural resource partnerships: factors leading to success in the management of landscape level ecosystems involving mixed ownership. Staff paper Series 113. University of Minnesota, Department of Forest Resources, St. Paul, Minnesota, USA.

Working Group 2.9-Public Participation. 2002. Public participation in relation to the Water Framework Directive. Common Implementation Strategy (CIS) for the Water Framework Directive. Guidance document No. 8. Office for Official Publications of the European Communities, Luxembourg. [online] URL: http://circa.europa.eu/Public/irc/ env/wfd/library?l=/framework_directive/guidance_documents/ guidancesnos8spublicspar/ EN $1.0 \quad \& a=d$ 